\title{
Biomarkers to Target Heterogeneous Breast Cancer Stem Cells
}

\author{
Wendy W. Hwang-Verslues ${ }^{1 *}$, Wen-Hwa Lee ${ }^{2}$ and Eva Y.-H.P. Lee ${ }^{2}$ \\ ${ }^{1}$ Genomics Research Center, Academia Sinica, No. 128, Sec. 2, Academia Road, Taipei 115, Taiwan \\ ${ }^{2}$ Department of Biological Chemistry, University of California, Irvine, CA 92697, USA
}

\begin{abstract}
Breast cancer is the most common cancer and the second leading cause of death in U.S. women. Due to early detection and advanced treatment, the breast cancer death rate has been declining since 1990. However, disease recurrence is still the major obstacle in moving from therapy to truly curative treatments. Recent evidence has indicated that breast cancer recurrence is often caused by a subpopulation of breast cancer cells. This subset of cancer cells, usually referred to asbreast cancer stem cells (BCSCs), exhibits stem cell phenotypes. They can self-renew and asymmetrically divide to more differentiated cancer cells. These cells are also highly resistant to conventional therapeutic reagents. Therefore, identifying and characterizing these BCSC subpopulations within the larger population of breast cancercells is essential for developing new strategies to treat breast cancer and prevent recurrence.In this review article, we discuss the current proposed model for the origin of tumor heterogeneity, summarize the recent findings of cell surface and cytoplasmic markers for BCSC identification, review the regulatory mechanisms by which BCSCs maintain or non-cancer stem cells acquire BCSC characteristics, describe the proposed strategies to eliminate BCSCs, and highlight the current limitations and challenges to translate basic BCSC research to clinical application including establishment of clinical biomarkers and therapeutic treatments specifically targeting BCSCs.
\end{abstract}

\section{Introduction}

\section{A hybrid model for the origin of tumor heterogeneity}

There are two concepts for explaining tumor heterogeneity: the CSC hypothesis and clonal evolution model [1,2]. The CSC hypothesis proposes that CSCs share similarproperties with normal stem cells in termsof their unlimited capacity for self-renewal [1]. They can also divide asymmetrically togenerate differentiated cancer cells which contribute to the heterogeneity of tumor. These CSCs can promote tumor progression, heterogeneity, drug resistance, recurrence, and metastasis [3-9]. On the other hand, the clonal evolution model hypothesizes that cancer originates from any cell type. These cells accumulate various mutations stepwise over time and through genetic instability acquireCSC characteristics necessary to adapt to stress and the changes of microenvironment. Thus, it is the most adaptivecells within the heterogeneous cancer cells that are responsible for tumor progression and relapses [10]. Each model has supporting evidence; however, new evidence indicates thata hybrid model combining these two hypotheses best describes tumor heterogeneity.

Cancer initiation and progression often is a result of deregulated self-renewal pathways in normal stem cells or due to carcinogenic mutations in other cell types [1]. In some cases, genetic mutations can activate self-renewal pathways and preserve the epigenetic programs that regulate asymmetric cell divisions thus producing cancer stem cells capable of generating heterogeneous cancer cells.In other cases, mutations cause inhibition of differentiation and allow cancer cells to maintain proliferative potential which avoids hierarchical organization [11]. Thus, whether a cancer more closely follows the CSC hypothesis or clonal evolution concept depends on the cell of origin (a.k.a. tumorinitiating cell) as well as the specific genetic mutations acquired and their consequences. Whichever is the dominant model, investigating the underlying mechanisms of BCSC characteristics will allow us to further understand how breast cancer cells propagate and identify new biomarkers and therapeutic targets.

\section{Identification of heterogeneous BCSCs}

Work in hematopoietic stem cells using cell surface markers has made it possible to identify a differentiation hierarchy of cell lineage with defined functional characteristics [12]. In the mammary gland, a similar stem/progenitor/differentiated cell hierarchy has been described [13-16]. Using specific cell surface markers and fluorescenceactivated cell sorting (FACS) to isolate mammary stem cells from mice, the concept of a single mammary stem cell being able to reconstitute the whole mammary gland was validated $[15,16]$. Subsequently, mammary progenitor cells specific for myoepithelial/basal or luminal lineage have also been characterized in mice [17-19].

To isolate and characterize BCSCs, surface markers in combination with cell sorting and assays including soft agar colony formation, mammosphere formation, epithelial-mesenchymal transition (EMT) marker expression, asymmetric cell division and mouse xenotransplantation and tumorigenesis assays are used. The first and most commonly used markers to enrich BCSCs are CD44 and CD24 [20]. Cells with a specific pattern ofthese markers (CD44 $\mathrm{CD} 24^{-/ \text {low }}$, epithelial specificantigen $(\mathrm{ESA})^{+}$) but lacking expression of specific lineage markers ( $\mathrm{Lin}^{-}$) exhibited EMT phenotypes [21]. These cancer cells also had higher tumorigenic potential thanbulk tumor cells after transplantation in nonobese diabetic/severe combined immunodeficient (NOD/SCID) mice [20,21]. In a low attachment in vitro culture system, these cancer cells were able to form clonal nonadherent mammospheres which were more tumorigenic than established breast cancer-derived cell linesincluding MCF-7 and B3R [22].

*Corresponding author: Wendy W. Hwang-Verslues, Ph.D., Genomics Research Center, Academia Sinica, No. 128, Sec. 2, Academia Road, Taipei 115, Taiwan, Tel: 886-2-2789-8777; E-mail: wendyhv@gate.sinica.edu.tw

Received May 21, 2012; Accepted July 26, 2012; Published July 28, 2012

Citation: Hwang-Verslues WW, Lee WH, Lee EYHP (2012) Biomarkers to Target Heterogeneous Breast Cancer Stem Cells. J Mol Biomarkers Diagn S8:006. doi:10.4172/2155-9929.S8-006

Copyright: (c) 2012 Hwang-Verslues WW, et al. This is an open-access article distributed under the terms of the Creative Commons Attribution License, which permits unrestricted use, distribution, and reproduction in any medium, provided the original author and source are credited 
After this discovery, many efforts have been put into additional marker identifications, both on the cell surface and in the cytoplasm, to further isolate BCSCs [23-29]. For example, protein C receptor (PROCR, a.k.a. CD201) was identified usinggene expression profiling of primary breast cancers [24]. CD133 was identified for BCSCs isolated from cell lines generated fromBrca1 $1^{\text {exon } 11} / \mathrm{p} 3^{+/-}$mouse mammary tumors [25]. The cytoplasmic marker aldehyde dehydrogenase (ALDH) was found increased in asubpopulation of both normal and cancerous human mammaryepithelial cells that exhibited stem/progenitor cell properties [23]. Some BCSCs also exhibited low proteasome activity [28]. These observations indicated that BCSCs themselves may be heterogeneous with different BCSC types present in different breast cancer subtypes. Our laboratory used a panel of known stem cell markers andfound that the expression of these markers varied greatly among breast cancer cell lines and primary tumors [26]. An association between metastasis status and a high prevalence of certain markers including CD $44^{+} / \mathrm{CD} 24^{-/ 10 w}, \mathrm{ESA}^{+}, \mathrm{CD} 133^{+}, \mathrm{C}-\mathrm{X}-\mathrm{C}$ chemokine receptor type $4(\mathrm{CXCR} 4)^{+}$and $\mathrm{PROCR}^{+}$in primary tumor cells was also found. We further identified a highly malignant BCSC subpopulationfrom MDA-MB-231 cells with a $\mathrm{PROCR}+\mathrm{ESA}^{+}$marker signature rather than the previously identified $\mathrm{CD} 44^{+} / \mathrm{CD} 24^{-/ \text {low }}$ and ALDH pattern. This $\mathrm{PROCR}^{+} / \mathrm{ESA}^{+} \mathrm{BCSC}$ subpopulation was highly enriched with cancer stem/progenitor cell populations. Our results suggested that similar to leukemia, several stem/progenitor cell-like subpopulations can exist in breast cancer. In agreement with our study, Pece and coworkers [29] utilized the quiescent nature of normal mammary stem cells which can retain a lipophilic fluorescent dye $\mathrm{PKH} 26$ to further identify additional marker combinations for BCSC isolation. They found that CD24 $4^{\text {high }} /$ CD49 ${ }^{\text {high }} / \mathrm{DNER}(\Delta$-notch-like EGF repeat-containing transmembrane) high, $\mathrm{CD} 24^{\text {high }} / \mathrm{CD} 49^{\text {high }} / \mathrm{DLL} 1 \quad(\Delta \text {-like-1 })^{\text {high }}$, and $\mathrm{CD} 49 \mathrm{f}^{+} / \mathrm{DLL} \mathrm{L}^{\text {high }} /$ DNER $^{\text {high }}$ can be used as markers and provided additional evidence for the concept of BCSC heterogeneity. Whether these BCSC markers are associated with stem cell functions and characteristics, or just serve as a tool for BCSC identification needs to befurther investigated.

\section{Regulatory mechanisms to maintain or acquire BCSC characteristics}

The stem/progenitor/differentiated cell hierarchy is not a unidirectional system. It has been shown that normal mature epithelial cells can spontaneously revert to stem cells [30] suggesting a complex multidirectional relationship between stem/progenitors and differentiated cells. This plasticity also occurs in heterogeneous cancer cells. The seemingly reverse transition from cancer cell without stem-like properties to CSC has recently been described [21,31]. Thus, CSCs are not a fixed population. Depending on genetic and epigenetic changes or microenvironment stimuli, cancer cells are able to shift between stem-like and non-stem-like states [32] (Figure 1).

Genetic changes: Consistent with the invasive nature of CSCs, EMT is able to drive cancer cells to acquire CSC characteristics. EMT is also important in maintaining CSC subpopulations. For example, expression of SLUG/SNAI2, TWIST, CD146 and Kruppel-like factor 4 (KLF4), which promote EMT and invasion, can drive cancer cells to express the $\mathrm{CD}^{4} 4^{+} / \mathrm{CD} 24^{-} \mathrm{BCSC}$ markers and exhibit BCSC phenotypes [33-36]. Many oncogene overexpression or tumor suppressor gene mutations also contribute to this aspect. For instance, oncogene human epidermal growth factor receptor 2 (HER2) overexpressioncan drive cancer cells to have higher ALDH activity and BCSC characteristics [37]. Loss of tumor suppressor p53 was found to be correlated with an increase in the expression of EMT genes and stemness markers in breast cancer cells [38].

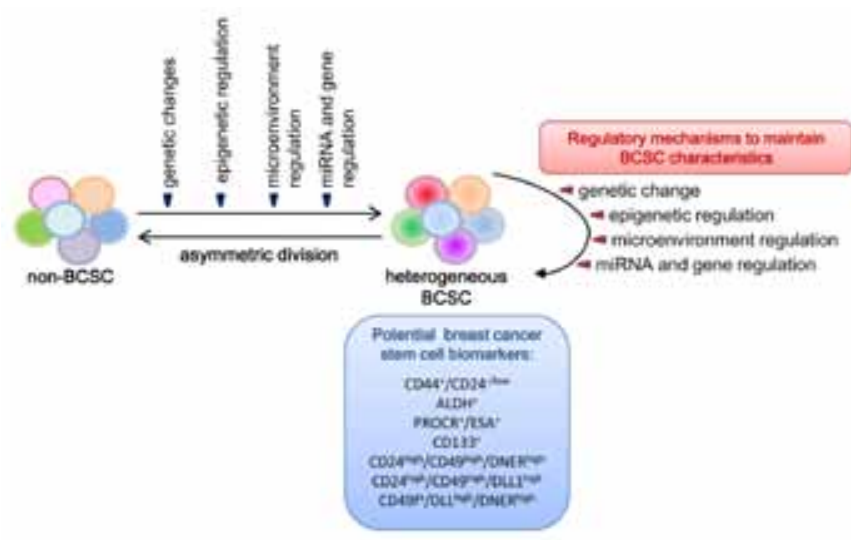

Figure 1: A complex multidirectional relationship between differentiated cancer cells and heterogeneous BCSCs. Depending on genetic and epigenetic changes, miRNA and gene regulation or microenvironment stimuli, cancer cells are able to shift between stem-like and non-stemlike states. This plasticity contributes to the heterogeneity of BCSCs. The regulatory mechanisms underlying the shift from non-BCSCs to BCSCs also play important roles in maintaining the BCSC pool and its characteristics. The currently used cell surface markers for BCSC identification could be potentially useful clinical biomarkers.

Epigenetic regulation: Besides genetic changes, epigenetic regulation also determines BCSC properties. Polycomb repressor proteins have been shown to play an important role in maintaining the self-renewal capability of stem cells [39-42]. Enhancer of zeste homolog 2 (EZH2), a key component of the polycomb repressor complex (PRC) 2 which mediates histone $\mathrm{H} 3$ methylation at lysine 27 (H3K27), has been linked to aggressive progression of breast and prostate cancers $[43,44]$. Recent evidence demonstrated that EZH2 epigenetically downregulated DNA damage repair protein Rad51 leading to activated extracellular signal-regulated kinase (ERK)- $\beta$-catenin signaling which resulted in BCSC population expansion [45]. In addition, epigenetic inactivation of the tumor suppressorbreast cancer 1 (BRCA1) gene due to $\mathrm{CpG}$ island hypermethylation in breast cancer was observed [46,47]. These BRCA1 defective breast cancers contained expanded luminal progenitor cells [48]. These findings demonstrated a BCSC regulatory mechanism linking genetic aberration, epigenetic regulation and DNA repair defects.

Microenvironment regulation: In addition to genetic and epigenetic regulation of the mammary stem/progenitor cells, autocrine signaling of these cells, paracrine signaling from thesurrounding differentiated cells and the microenvironment alsocontributes to the regulation of self-renewal and differentiation [49-53]. For example, hypoxia of the tumor microenvironment has been shown to enrich CSC subpopulations and induce CSC phenotypes in many solid tumors. Anti-angiogenesis agents which cause intratumoral hypoxia resulted in an increase in BCSC prevalence via activation of the Akt$\beta$-catenin pathway and promoted an invasive phenotype [54]. Hypoxia also caused expansion of CSC subpopulation via up-regulation of embryonic stem cell-like transcription factors including octamerbinding transcription factor 4 (OCT4), NANOG, sex determining region Y-box 2 (SOX2), KLF4 and Lin-28 [55]. In addition to hypoxia, inflammation also plays a role in regulating CSCs. For example, tumor-associated macrophages promoted CSC phenotypes including tumorigenesis and drug resistance through their downstream factors interleukin (IL)-6 and milk-fat globule-epidermal growth factor- 8 
which activated the signal transducer and activator of transcription 3 (STAT3) and Sonic Hedgehog pathways in CSCs [56].

Paracrine/autocrine signaling pathways between surrounding stromas/non-BCSCs and BCSCs are also important in regulating BCSC phenotypes.BCSC secreted IL- 6 was found to convert breast cancer progenitor cells to a more BCSC-like phenotype through a positive feedback loop among nuclear factor of kappa light polypeptide gene enhancer in B-cells (NF- $\kappa$ B), Lin-28 and let-7 miRNA [57]. Recently, cancer associated fibroblasts (CAFs) were found to secret chemokine (C-C motif) ligand 2 (CCL2) and stimulate the stem cell-specific, sphere-forming phenotype and BCSC self-renewal through induction of NOTCH1 expression [58]. In addition, mesenchymal stem cells (MSCs) have been found in the tumor-associated stroma in breast cancer. Breast cancer cells stimulatedMSCs to secret chemokine CCL5, which then acts in a paracrine fashion on the chemokine receptor CCR5 in cancer cells to promote their metastatic potency [59]. Also, endothelial cells contribute to the BCSC regulation by increasing the expression of metaphase cell-cycle genes in CD44/CD24-BCSCs. These endothelial cells promoted cancer cell proliferation by secreting platelet-derived growth factor subunit B (PDGFB), which was stimulated by cancer cell-secreted vascular endothelial growth factor (VEGF), fibroblast growth factor 12 (FGF12), pleiotrophin (PTN) and neurofibromin 1 (NF1) [60].

micro-RNA and gene regulation: Likewise, micro-RNAs (miRNAs) contributing to the promotion or maintenance of stemness of cancer cells have also been found. In many cases, miRNAs possessing tumor suppressor functions were down-regulated and those exhibiting oncogenic functions up-regulated in BCSC subpopulations. This differential miRNA expression contributed to maintenance of the BCSC population as well as stem cell phenotypes. In mouse mammary stem/progenitor cells, both miR-205 and miR-22 were highly expressed whereas miR-93 and let-7 were down-regulated [61]. Over-expression of miR-205 increased the progenitor cell population [62]. Similarly,in human breast cancers, tumor suppressor miRNA let-7 which inhibits self-renewal capacity and promotes differentiation by repressing $\mathrm{H}$-Ras and high mobility group AT-hook 2 (HMGA2)was found to be downregulated in the CD $44^{+} / \mathrm{CD} 24^{- \text {llow }}$ BCSCs [63]. Shimono and coworkers found 37 miRNAs differentially expressed between BCSCs and non-BCSCs. Among these miRNAs,miR-200c was found to inhibit BMI1 polycomb ring finger oncogene (BMI1), a regulator of stem cell self-renewal, and led to inhibition of clonal expansion of breast cancer cells in vitro, and strongly suppressed the tumor formation driven by BCSCs in vivo [64].miR-200 has also been found to downregulate suppressor of zeste 12 homolog (Suz12), a subunit of a polycomb repressor complex, which has important roles in BCSC formation and maintenance [65]. However, the importance of other differentially expressed miRNAs in BCSCs remains to be determined.

To identify a general mechanism ofpromoting BCSC phenotypes, we compared the miRNA expression profile of $\mathrm{PROCR}^{+} / \mathrm{ESA}^{+} \mathrm{BCSC}$ subpopulation [26] with that of the $\mathrm{CD} 44^{+} / \mathrm{CD} 24^{-/ \text {low }}$ BCSC subpopulations [64]. This strategy allowed us to elucidate molecular mechanisms that are either shared among different BCSCs or unique to the highly tumorigenic $\mathrm{PROCR}^{+} / \mathrm{ESA}^{+}$subpopulation. We identified miR-495 as an oncogenic miRNA upregulated in both the $\mathrm{PROCR}^{+} / \mathrm{ESA}^{+}$and $\mathrm{CD}^{+} 4^{+} / \mathrm{CD} 24^{- \text {-low }}$ BCSC sub-populations[66]. Using multiple cell lines expressing different stem cell markers, we found that, regardless of cellular context, miR-495 could maintain or promote colony-forming ability, promote EMT marker expression, downregulate E-cadherin and suppress DNA-damage-inducible transcript 4 (DDIT4, a.k.a. REDD1)to confer hypoxia tolerance. These observations further suggested that although heterogeneous BCSCs might have dissimilar ability in tumorigenicity, migration and invasion, and maybe associated with different subtypes of breast cancers, there may be shared regulatory pathways that maintain BCSC phenotypes.

\section{Targeting breast cancer stem cells}

Biopsies from patients treated with neoadjuvant chemotherapy showed enrichment of BCSCs $[63,67]$. Similarly, enrichment of BCSCs was also found in tumors spontaneously developed or engrafted in animals receiving chemotherapy or radiation treatment, respectively $[68,69]$. The conversion of non-BCSCs to BCSCs was more prevalent after endocrine therapy [27,70-72]. Thus, the inherent resistance of BCSCs to chemo- and radiotherapy could be the major source of disease recurrence.

Many efforts have been put into finding treatments to eliminate BCSCs. Two major approaches have been used: 1, drug screening to identify chemicals selectively toxic to BCSCs and 2, targeting specific regulatory factorsinvolved in regulating BCSC phenotypes. For example, Gupta and colleagues [73] utilized a chemical screen to identify drugs with selective toxicity for BCSCs and found that salinomycin was able to reduce the prevalence of $\mathrm{CD} 44^{+} / \mathrm{CD} 24$ BCSCs compared to paclitaxel, a commonly used breast cancer chemotherapeutic agent. More recently, a combinatorial therapy with conventional chemotherapeutic agent and the anti-diabetic drug metformin has been shown to efficiently eliminate drug-resistant CD $44^{+} / \mathrm{CD} 24^{-}$cancer stem/progenitor cells in breast cancers [74, 75].

Investigation of differential gene expression between CSCs and non-CSCs makes it possible to find potential therapeutic targets. For example, gene expression profiling indicated that CXCR1, a cytokine IL- 8 receptor, was up-regulated in $\mathrm{ALDH}^{+} \mathrm{BCSCs}$. Moreover, recombinant IL-8 treatment increased the BCSC subpopulation and promoted its invasion ability [76]. Wicha's group used either a CXCR1-specific blocking antibody or repertaxin, a small-molecule CXCR1 inhibitor, to block CXCR1 and found that the ALDH ${ }^{+} \mathrm{BCSC}$ subpopulation was selectively depleted and this was mediated by the FAK/AKT/FOXO3A pathway [77]. Polyak's group identified 15 genes required for cell growth or proliferation in $\mathrm{CD} 44^{+} \mathrm{CD} 24$-BCSCs in a large-scale loss-of-function screen. They found that inhibition of several of these such as IL6, prostaglandin I2 synthase (PTGIS), hyaluronan synthase 1 (HAS1), CXCL3, and 6-phosphofructo-2-kinase/fructose2,6-biphosphatase 3 (PFKFB3) reduced STAT3 activation suggesting that the IL-6/JAK2/STAT3 pathway was preferentially active in CD $44^{+} \mathrm{CD} 24$-BCSCs. Indeed, inhibition of JAK2 was able to decrease theCD44 ${ }^{+} \mathrm{CD} 24-\mathrm{BCSC}$ number and block growth of xenografts [78]. More recently, Hung's group showed that BIKDD, a constitutively active mutant form of proapoptotic gene, BIK, significantly reducedCD $44^{+} /$ CD24- BCSCs through co-antagonism of its binding partners B-cell CLL/lymphoma 2 (Bcl-2), Bcl-xL, and myeloid cell leukemia sequence 1 (Mcl-1), suggesting a potential therapeutic strategy targeting BCSCs [79].

Although these approaches are worthwhile to developtargeted therapies, there are some limitations. As described above, BCSCs are heterogeneous and different BCSCs may be associated with different subtypes of breast cancers. Most of the studies only focused on one specific type of BCSCs, i.e., CD44 ${ }^{+} / \mathrm{CD} 24^{-}$subpopulation. Whether the potential therapeutic targets possess the same efficacy among different types of BCSCs remains to be determined. Thus, identification of the shared mechanism in different types of BCSCs, especially the regulation 
in self-renewal and asymmetric division, is important for treatment design. Moreover, whether therapies deplete BCSC by inducing cell death or promoting differentiation can be important in determining the treatment efficacy. As discussed above, BCSCs can arise from more differentiated cancer cells [30] to maintain the dynamic equilibrium between BCSCs and non-BCSCs [80]. The plasticity and adaptability ofaggressive cancer cells with BCSC phenotypes, in combinationwith genomic instability, may reduce the treatment efficacy. If the targeted therapies deplete BCSCs by causing BCSC specific cell death, this may promote the transient-amplifying cancer cells to convert to BCSC-like cells. Thus, therapies which induce BCSC differentiationor target the pathway regulating the plasticity may be more favorable.

While designing targeted therapies based on BCSC phenotypes and the regulatory pathways, one should also take the tumor microenvironment into account. Our laboratory, along with others, has shown that the cancer associated fibroblasts can promote tumorigenesis as well as BCSC phenotypes via paracrine signaling [58,81,82]. Thus, a combination of treatmentskilling bulk cancer cells, targeting BCSCs and their surrounding microenvironment may be the most efficient way to treat cancer.

\section{Final Remark}

In this exciting field, the number ofcell surface markers for identifying BCSCs are growing exponentially. The ultimate goal is to use the best reliable BCSC markers as biomarkers for clinical use (Figure 1). However, whether the current BCSC markers can be used as biomarkers remains to be determined. By definition, the best biomarker is a unique molecular signature that can be unambiguously correlated to biological events in order to validate novel drug targets, predict drug response, and eventually help therapeutic decision making [83]. Thus, a BCSC biomarker will need to be reproducible and measurable in clinical samples to detect the BCSC subpopulation which determines outcomes from cancer or responses to treatment $[84,85]$. As discussed above, the current system to identify, isolate and studyrelatively rare BCSCsfrom primary specimens remain difficult for clinical practice.Unless a better system can be established to perform large cohort studies for profiling the heterogeneous BCSCs and their corresponding breast cancer types, the currently identified BCSC markersmay not meet the need for establishment of clinically relevant biomarkers. Thus, continuing effort in identifyingfunctional markers involved in regulating BCSC phenotypes and improving BCSC identification methodology is also essential in moving our new knowledge of BCSCs from laboratory to clinical practice.

Specifically targeting BCSCs for therapeutic treatment relies on characterizing BCSCs and their microenvironment. Continuing efforts in identifying heterogeneous BCSCsand their genetic/epigenetic similarities and differences are needed. To achieve this, the limitations in current methods and techniques for BCSC identification have to be conquered. One key limitation is that there is yet no suitable system to maintain primary BCSCs in long term culture for detailed mechanistic studies. Limited availability of primary specimens, in addition to the low prevalence of BCSCs, makes many methods not easily applicable in routine practice for large cohort studies. Most experiments must instead rely on a relatively small number of immortalized human breast cancer cell lines. As new evidence has indicated the importance of the BCSC niche in BCSC regulation, identification and characterization, the stromal or endothelial cells surrounding BCSC may be useful for improving long term culture for mechanistic studies.

\section{Acknowledgements}

This work was supported by Academia Sinica (Taiwan) and NIH grants to EL (CA137102) and WHL (CA94170). WWHV was supported by an Academia Sinica Postdocotral Research Fellowship. WHL declares that he serves as a member of Board of Directors of the biotech company, GeneTex. This arrangement has been reviewed and approved by $\mathrm{UCl}$ conflict of interest committee.

\section{References}

1. Reya T, Morrison SJ, Clarke MF, Weissman IL (2001) Stem cells, cancer, and cancer stem cells. Nature 414: 105-111.

2. Merlo LM, Pepper JW, Reid BJ, Maley CC (2006) Cancer as an evolutionary and ecological process. Nat Rev Cancer 6: 924-935.

3. Wicha MS, Liu S, Dontu G (2006) Cancer stem cells: an old idea--a paradigm shift. Cancer Res 66: 1883-1890.

4. Clarke MF, Dick JE, Dirks PB, Eaves CJ, Jamieson CH, et al. (2006) Cancer stem cells--perspectives on current status and future directions: AACR Workshop on cancer stem cells. Cancer Res 66: 9339-9344.

5. Campbell LL, Polyak K (2007) Breast tumor heterogeneity: cancer stem cells or clonal evolution? Cell Cycle 6: 2332-2338.

6. Kakarala M, Wicha MS (2008) Implications of the cancer stem-cell hypothesis for breast cancer prevention and therapy. J Clin Oncol 26: 2813-2820.

7. 5Hwang-Verslues WW, Chang KJ, Lee EY, Lee WH (2008) Breast cancer stem cells and tumor suppressor genes. J Formos Med Assoc 107: 751-766.

8. Clevers $H$ (2011) The cancer stem cell: premises, promises and challenges Nat Med 17: 313- 319

9. Visvader JE, Lindeman GJ (2010) Stem cells and cancer - the promise and puzzles. Mol Oncol 4: 369-372.

10. Nowell PC (1976) The clonal evolution of tumor cell populations. Science 194 23-28

11. Shackleton M, Quintana E, Fearon ER, Morrison SJ (2009) Heterogeneity in cancer: cancer stem cells versus clonal evolution. Cell 138: 822-829.

12. Bonnet D, Dick JE (1997) Human acute myeloid leukemia is organized as a hierarchy that originates from a primitive hematopoietic cell. Nat Med 3: 730737

13. Tsai YC, Lu Y, Nichols PW, Zlotnikov G, Jones PA, et al. (1996) Contiguous patches of normal human mammary epithelium derived from a single stem cell: implications for breast carcinogenesis. Cancer Res 56: 402-404.

14. Kordon EC, Smith GH (1998) An entire functional mammary gland may comprise the progeny from a single cell. Development 125: 1921-1930.

15. Shackleton M, Vaillant F, Simpson KJ, Stingl J, Smyth GK, et al. (2006) Generation of a functional mammary gland from a single stem cell. Nature 439 : 84-88

16. Stingl J, Eirew P, Ricketson I, Shackleton M, Vaillant F, et al. (2006) Purification and unique properties of mammary epithelial stem cells. Nature 439: 993-997.

17. Sleeman KE, Kendrick H, Robertson D, Isacke CM, Ashworth A, et al. (2007) Dissociation of estrogen receptor expression and in vivo stem cell activity in the mammary gland. J Cell Biol 176: 19-26.

18. Sleeman KE, Kendrick H, Ashworth A, Isacke CM, Smalley MJ (2006) CD24 staining of mouse mammary gland cells defines luminal epithelial, myoepithelial/ basal and non-epithelial cells. Breast Cancer Res 8: R7.

19. Asselin-Labat ML, Sutherland KD, Barker $H$, Thomas $R$, Shackleton $M$, et al. (2007) Gata-3 is an essential regulator of mammary-gland morphogenesis and luminal-cell differentiation. Nat Cell Biol 9: 201-209.

20. Al-Hajj M, Wicha MS, Benito-Hernandez A, Morrison SJ, Clarke MF (2003) Prospective identification of tumorigenic breast cancer cells. Proc Natl Acad Sci U S A 100: 3983-3988.

21. Mani SA, Guo W, Liao MJ, Eaton EN, Ayyanan A, et al. (2008) The epithelialmesenchymal transition generates cells with properties of stem cells. Cell 133 704-715.

22. Ponti D, Costa A, Zaffaroni N, Pratesi G, Petrangolini G, et al. (2005) Isolation and in vitro propagation of tumorigenic breast cancer cells with stem/progenitor cell properties. Cancer Res 65: 5506-5511. 
Citation: Hwang-Verslues WW, Lee WH, Lee EYHP (2012) Biomarkers to Target Heterogeneous Breast Cancer Stem Cells. J Mol Biomarkers Diagn S8:006. doi:10.4172/2155-9929.S8-006

Page 5 of 6

23. Ginestier C, Hur MH, Charafe-Jauffret E, Monville F, Dutcher J, et al. (2007) ALDH1 is a marker of normal and malignant human mammary stem cells and a predictor of poor clinical outcome. Cell Stem Cell 1: 555-567.

24. Shipitsin M, Campbell LL, Argani P, Weremowicz S, Bloushtain-Qimron N, et al. (2007) Molecular definition of breast tumor heterogeneity. Cancer Cell 11 : 259-273.

25. Wright MH, Calcagno AM, Salcido CD, Carlson MD, Ambudkar SV, et al (2008) Brca1 breast tumors contain distinct CD44+/CD24- and CD133+ cells with cancer stem cell characteristics. Breast Cancer Res 10: R10.

26. Hwang-Verslues WW, Kuo WH, Chang PH, Pan CC, Wang $\mathrm{HH}$, et al. (2009) Multiple lineages of human breast cancer stem/progenitor cells identified by profiling with stem cell markers. PLoS One 4: e8377.

27. Creighton CJ, Li X, Landis M, Dixon JM, Neumeister VM, et al. (2009) Residual breast cancers after conventional therapy display mesenchymal as well as tumor-initiating features. Proc Natl Acad Sci U S A 106: 13820-13825.

28. Vlashi E, Kim K, Lagadec C, Donna LD, McDonald JT, et al. (2009) In vivo imaging, tracking, and targeting of cancer stem cells. J Natl Cancer Inst 101 350-359

29. Pece S, Tosoni D, Confalonieri S, Mazzarol G, Vecchi M, et al. (2010) Biological and molecular heterogeneity of breast cancers correlates with their cance stem cell content. Cell 140: 62-73.

30. Chaffer CL, Brueckmann I, Scheel C, Kaestli AJ, Wiggins PA, et al. (2011) Normal and neoplastic nonstem cells can spontaneously convert to a stem-like state. Proc Natl Acad Sci U S A 108: 7950-7955.

31. Morel AP, Lievre M, Thomas C, Hinkal G, Ansieau S, et al. (2008) Generation of breast cancer stem cells through epithelial-mesenchymal transition. PLoS One 3: e2888

32. Scheel C, Weinberg RA (2011) Phenotypic plasticity and epithelialmesenchymal transitions in cancer and normal stem cells? Int J Cancer 129 2310-2314.

33. Bhat-Nakshatri P, Appaiah H, Ballas C, Pick-Franke P, Goulet R, et al. (2010) SLUG/SNAI2 and tumor necrosis factor generate breast cells with CD44+/ CD24- phenotype. BMC Cancer 10: 411.

34. Zeng Q, Li W, Lu D, Wu Z, Duan H, et al. (2012) CD146, an epithelialmesenchymal transition inducer, is associated with triple-negative breast cancer. Proc Natl Acad Sci U S A 109: 1127-1132.

35. Yu F, Li J, Chen H, Fu J, Ray S, et al. (2011) Kruppel-like factor 4 (KLF4) is required for maintenance of breast cancer stem cells and for cell migration and invasion. Oncogene 30: 2161-2172.

36. Yang MH, Hsu DS, Wang HW, Wang HJ, Lan HY, et al. (2010) Bmi1 is essential in Twist1-induced epithelial-mesenchymal transition. Nat Cell Biol 12: 982-992.

37. Korkaya H, Paulson A, lovino F, Wicha MS (2008) HER2 regulates the mammary stem/progenitor cell population driving tumorigenesis and invasion. Oncogene 27: 6120-6130.

38. Chang CJ, Chao CH, Xia W, Yang JY, Xiong Y, et al. (2011) p53 regulates epithelial-mesenchymal transition and stem cell properties through modulating miRNAs. Nat Cell Biol 13: 317-323.

39. Cao R, Zhang $Y(2004)$ The functions of $E(Z) / E Z H 2-$ mediated methylation of lysine 27 in histone H3. Curr Opin Genet Dev 14: 155-164.

40. Ezhkova E, Pasolli HA, Parker JS, Stokes N, Su IH, et al. (2009) Ezh2 orchestrates gene expression for the stepwise differentiation of tissue-specific stem cells. Cell 136: 1122-1135.

41. Lessard J, Sauvageau G (2003) Polycomb group genes as epigenetic regulators of normal and leukemic hemopoiesis. Exp Hematol 31: 567-585.

42. Sparmann A, van Lohuizen M (2006) Polycomb silencers control cell fate, development and cancer. Nat Rev Cancer 6: 846-856.

43. Kleer CG, Cao Q, Varambally S, Shen R, Ota I, et al. (2003) EZH2 is a marker of aggressive breast cancer and promotes neoplastic transformation of breast epithelial cells. Proc Natl Acad Sci U S A 100: 11606-11611.

44. Varambally S, Dhanasekaran SM, Zhou M, Barrette TR, Kumar-Sinha C, et al. (2002) The polycomb group protein EZH2 is involved in progression of prostate cancer. Nature 419: 624-629.

45. Chang CJ, Yang JY, Xia W, Chen CT, Xie X, et al. (2011) EZH2 promotes expansion of breast tumor initiating cells through activation of RAF1-betacatenin signaling. Cancer Cell 19: 86-100.

46. Esteller M (2000) Epigenetic lesions causing genetic lesions in human cancer: promoter hypermethylation of DNA repair genes. Eur J Cancer 36: 2294-2300.

47. Birgisdottir V, Stefansson OA, Bodvarsdottir SK, Hilmarsdottir H, Jonasson JG et al. (2006) Epigenetic silencing and deletion of the BRCA1 gene in sporadic breast cancer. Breast Cancer Res 8: R38.

48. Lim E, Vaillant F, Wu D, Forrest NC, Pal B, et al. (2009) Aberrant lumina progenitors as the candidate target population for basal tumor development in BRCA1 mutation carriers. Nat Med 15: 907-913.

49. Asselin-Labat ML, Vaillant F, Sheridan JM, Pal B, Wu D, et al. (2010) Contro of mammary stem cell function by steroid hormone signalling. Nature 465: 798-

50. Joshi PA, Jackson HW, Beristain AG, Di Grappa MA, Mote PA, et al. (2010) Progesterone induces adult mammary stem cell expansion. Nature 465: 803807.

51. Scheel C, Eaton EN, Li SH, Chaffer CL, Reinhardt F, et al. (2011) Paracrine and autocrine signals induce and maintain mesenchymal and stem cell states in the breast. Cell 145: 926-940.

52. Spradling A, Drummond-Barbosa D, Kai T (2001) Stem cells find their niche Nature 414: 98-104

53. Forsberg EC, Prohaska SS, Katzman S, Heffner GC, Stuart JM, et al. (2005) Differential expression of novel potential regulators in hematopoietic stem cells PLoS Genet 1: e28.

54. Conley SJ, Gheordunescu E, Kakarala P, Newman B, Korkaya H, et al. (2012) Antiangiogenic agents increase breast cancer stem cells via the generation of tumor hypoxia. Proc Natl Acad Sci U S A 109: 2784-2789.

55. Mathieu J, Zhang Z, Zhou W, Wang AJ, Heddleston JM, et al. (2011) HIF induces human embryonic stem cell markers in cancer cells. Cancer Res 71 $4640-4652$.

56. Jinushi M, Chiba S, Yoshiyama H, Masutomi K, Kinoshita I, et al. (2011) Tumor-associated macrophages regulate tumorigenicity and anticancer drug responses of cancer stem/initiating cells. Proc Natl Acad Sci USA 108: 12425 12430.

57. Iliopoulos D, Hirsch HA, Wang G, Struhl K (2011) Inducible formation of breast cancer stem cells and their dynamic equilibrium with non-stem cancer cells via IL6 secretion. Proc Natl Acad Sci USA 108: 1397-1402.

58. Tsuyada A, Chow A, Wu J, Somlo G, Chu P, et al. (2012) CCL2 mediates cross-talk between cancer cells and stromal fibroblasts that regulates breast cancer stem cells. Cancer Res 72: 2768-2779.

59. Karnoub AE, Dash AB, Vo AP, Sullivan A, Brooks MW, et al. (2007) Mesenchymal stem cells within tumour stroma promote breast cance metastasis. Nature 449: 557-563.

60. Buess M, Rajski M, Vogel-Durrer BM, Herrmann R, Rochlitz C (2009) Tumorendothelial interaction links the CD44(+)/CD24(-) phenotype with poor prognosis in early-stage breast cancer. Neoplasia 11: 987-1002.

61. Ibarra I, Erlich Y, Muthuswamy SK, Sachidanandam R, Hannon GJ (2007) A role for microRNAs in maintenance of mouse mammary epithelial progenitor cells. Genes Dev 21: 3238-3243.

62. Greene SB, Gunaratne PH, Hammond SM,Rosen JM (2010) A putative role fo microRNA-205 in mammary epithelial cell progenitors. J Cell Sci 123: 606-618.

63. Yu F, Yao H, Zhu P, Zhang X, Pan Q, et al. (2007) let-7 regulates self renewal and tumorigenicity of breast cancer cells. Cell 131: 1109-1123.

64. Shimono Y, Zabala M, Cho RW, Lobo N, Dalerba P, et al. (2009) Downregulation of miRNA-200c links breast cancer stem cells with normal stem cells. Cell 138 592-603.

65. Iliopoulos D, Lindahl-Allen M, Polytarchou C, Hirsch HA, Tsichlis PN, et al. (2010) Loss of miR-200 inhibition of Suz12 leads to polycomb-mediated repression required for the formation and maintenance of cancer stem cells Mol Cell 39: 761-772

66. Hwang-Verslues WW, Chang PH, Wei PC, Yang CY, Huang CK, et al. (2011) miR-495 is upregulated by E12/E47 in breast cancer stem cells, and promotes oncogenesis and hypoxia resistance via downregulation of E-cadherin and REDD1. Oncogene 30: 2463-2474. 
67. Li X, Lewis MT, Huang J, Gutierrez C, Osborne CK, et al. (2008) Intrinsic resistance of tumorigenic breast cancer cells to chemotherapy. J Natl Cancer Inst 100: 672-679.

68. Shafee N, Smith CR, Wei S, Kim Y, Mills GB, et al. (2008) Cancer stem cells contribute to cisplatin resistance in Brca1/p53-mediated mouse mammary tumors. Cancer Res 68: 3243-3250.

69. Zielske SP, Spalding AC, Wicha MS, Lawrence TS (2011) Ablation of breast cancer stem cells with radiation. Transl Oncol 4: 227-233.

70. O'Brien CS, Howell SJ, Farnie G, Clarke RB (2009) Resistance to endocrine therapy: are breast cancer stem cells the culprits? J Mammary Gland Biol Neoplasia 14: 45-54

71. Fillmore CM, Kuperwasser C (2008) Human breast cancer cell lines contain stem-like cells that self-renew, give rise to phenotypically diverse progeny and survive chemotherapy. Breast Cancer Res 10: R25.

72. Hiscox S, Jiang WG, Obermeier K, Taylor K, Morgan L, et al. (2006) Tamoxifen resistance in MCF7 cells promotes EMT-like behaviour and involves modulation of beta-catenin phosphorylation. Int J Cancer 118: 290-301.

73. Gupta PB, Onder TT, Jiang G, Tao K, Kuperwasser C, et al. (2009) Identification of selective inhibitors of cancer stem cells by high-throughput screening. Cell 138: 645-659.

74. Hirsch HA, lliopoulos D, Tsichlis PN, Struhl K (2009) Metformin selectively targets cancer stem cells, and acts together with chemotherapy to block tumor growth and prolong remission. Cancer Res 69: 7507-7511.

75. Vazquez-Martin A, Oliveras-Ferraros C, Del Barco S, Martin-Castillo B, Menendez JA (2011) The anti-diabetic drug metformin suppresses self-renewal and proliferation of trastuzumab-resistant tumor-initiating breast cancer stem cells. Breast Cancer Res Treat 126: 355-364.

76. Charafe-Jauffret E, Ginestier C, lovino F, Wicinski J, Cervera N, et al. (2009)
Breast cancer cell lines contain functional cancer stem cells with metastatic capacity and a distinct molecular signature. Cancer Res 69: 1302-1313.

77. Ginestier C, Liu S, Diebel ME, Korkaya H, Luo M, et al. (2010) CXCR1 blockade selectively targets human breast cancer stem cells in vitro and in xenografts. J Clin Invest 120: 485-497.

78. Marotta LL, Almendro V, Marusyk A, Shipitsin M, Schemme J, et al. (2011) The JAK2/STAT3 signaling pathway is required for growth of CD44+CD24- stem cell-like breast cancer cells in human tumors. J Clin Invest 121: 2723-2735.

79. Lang JY, Hsu JL, Meric-Bernstam F, Chang CJ, Wang Q, et al. (2011) BikDD eliminates breast cancer initiating cells and synergizes with lapatinib for breast cancer treatment. Cancer Cell 20: 341-356.

80. Yang G, Quan Y, Wang W, Fu Q, Wu J, et al. (2012) Dynamic equilibrium between cancer stem cells and non-stem cancer cells in human SW620 and MCF-7 cancer cell populations. Br J Cancer 106: 1512-1519.

81. Tyan SW, Kuo WH, Huang CK, Pan CC, Shew JY, et al. (2011) Breast cance cells induce cancer-associated fibroblasts to secrete hepatocyte growth factor to enhance breast tumorigenesis. PLoS One 6: e15313.

82. Orimo A, Gupta PB, Sgroi DC, Arenzana-Seisdedos F, Delaunay T, et al. (2005) Stromal fibroblasts present in invasive human breast carcinomas promote tumor growth and angiogenesis through elevated SDF-1/CXCL12 secretion. Cell 121: 335-348.

83. Frank R, Hargreaves R (2003) Clinical biomarkers in drug discovery and development. Nat Rev Drug Discov 2: 566-580.

84. Bast RC, Ravdin P, Hayes DF, Bates S, Fritsche H, et al. (2001) 2000 update of recommendations for the use of tumor markers in breast and colorectal cancer: clinical practice guidelines of the American Society of Clinical Oncology. J Clin Oncol 19: 1865-1878.

85. Hayes DF, Bast RC, Desch CE, Fritsche H, Kemeny NE, et al. (1996) Tumor marker utility grading system: a framework to evaluate clinical utility of tumor markers. J Natl Cancer Inst 88: 1456-1466.
This article was originally published in a special issue, Potential Biomarkers and Therapeutic Targets in Cancer Stem Cells handled by Editor(s). Dr. Murielle Mimeault, University of Nebraska Medical Center, USA 